of patients requiring these should be few, and as long as penicillin is effective should be preferred to the use of other antibiotics.-I am, etc.,

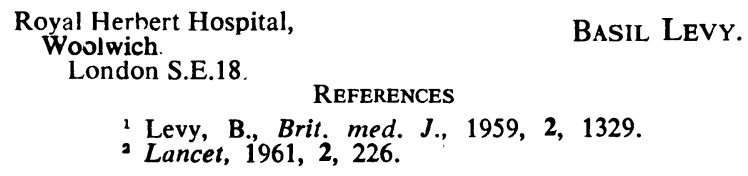

\section{Treatment of Ménière's Disease}

SIR,-I read with great interest the paper of $\mathrm{Mr}$. J. Angell James and his colleagues (November 24, p. 1343) as well as the letter of Mr. William McKenzie (December 22, p. 1680).

I quite agree with Mr. McKenzie that "new forms of surgery may lead to unnecessary operations" in Ménière's disease.

May I refer to the fairly good results which I have achieved with histamine injections in very small doses given subcutaneously and not intravenously as $\mathrm{Mr}$. McKenzie has done ? I published my results in the Hungarian Orvosi Hetilap, ${ }^{1}$ and my conclusion was that perhaps an allergic oedematous state of the labyrinth could cause the disease and so the histamine-desensitization may help to restore the patient's health by an allergic mechanism.

Naturally I suppose this is operative only in one part of the Ménière syndrome, and in the others different kinds of factors may be of influence.-I am, etc.,

\section{István Hospital, Margaret Halasy-LeHOCZKY. Budapest, Hungary. REFERENCE \\ ${ }^{1}$ Halasy-Lehoczky, M., Orv. Hetil., 1952, 93, 648.}

\section{Aversion Therapy for Homosexuality}

SIR,-Since it is now over nine months since the publication of "A Case of Homosexuality treated by Aversion Therapy" (March 17, 1962, p. 768), and 18 months since the treatment was carried out, we feel that a follow-up report would be of general interest. The methods of assessment have been written communications (B. J.), and a personal interview (D. F. E.), a social worker's visit to the patient's home, and a communication from his superior at work. (This last was a query regarding the advisability of promotion which would entail increased work and responsibility.)

We made inquiries under the following headings:

Sexual Drive : He has had no recurrence of his homosexual drives, although he has occasionally found Thimself admiring pretty boys. He is courting, and the relationship shows signs of becoming a very serious one. He has had sexual relations satisfactorily with his girlfriend, and he describes his feelings as of considerable phrsical satisfaction, though not having the same remotional component as his homosexual experiences.

Familv Relationships : These remain extremely good. It is reported that his recreational habits are now quite changed in that when he has no special engagement he spends a contented evening at home. This is in contrast to his previous way of life, which involved him in :almost nightly drinking with friends considered by his family to be undesirable. He now seems to have regained the complete trust of his family.

Work Record: He is highly thought of at his job and his promotion is imminent. His relationships with colleagues are cordial and there is no evidence of the

paranoid reaction feared by Dr. Sidney Crown (March 31, 1962, p. 943)

Mood: There has been no recurrence of the selfcriticism, etc., which led to his suicidal attempt prior to admission. A mood of confidence seems to have been maintained since the treatment.

It is our impression that this patient remains a sexually normal person, and that his general social adjustment is probably better than at any previous time.-We are, etc.,

Leeds.

Bristol.

SIR,-In the recent article on drugs for depression ("To-day's Drugs," January 19, p. 173), which was notable mainly for the nihilistic approach to treatment, particular exception may be taken to the harsh assessment of the hydrazine derivatives. I personally know several clinical psychiatrists with extensive experience of these drugs in a wide range of depressive syndromes who do not share these negative views. Naturally, there has been a considerable variation in reports on trials because of differences in dosage. in the duration of the trial period, and in the kind of cases selected for trial.

During the past four years your journal has contained excellent clinical descriptions of the kind of case most responsive to these drugs, together with indications of size and duration of dosage. ${ }^{1-4}$ There are available many other reports confirming these findings in conditions which Sargant ${ }^{3}$ has pointed out were particularly resistant to treatment before the hydrazine derivatives became available. The classification of these depressive syndromes is open to speculation, and one would not dispute that there are other depressive syndromes which are more responsive to the iminodibenzyl derivatives, but clinical experience indicates that there is a large group of psychiatric conditions where hydrazine derivatives are the current drugs of choice.

To say that these drugs are little more effective than placebos on the basis of a few selected reports. and that the depression is self-limiting anyway, is not an attitude that contributes to the fair assessment of a drug. It is well-known that belief in a drug can render a pharmacologically inactive compound apparently active, but less often realized that disbelief may counteract and even reverse established pharmacological effects-for example, a stimulant given to some subjects, who believe it is a sedative-can cause sedative effects. Further, the potentiation of a drug like pethidine is not a reason to abandon another active drug. but instead underlines the need for care in the administration of all drugs.

Finally, the article makes no mention of the hydrazine derivative "drazine," a very effective antidepressant with, in my experience, negligible side-effects.-I am, etc.,

Birmingham 13.

NORMAN W. IMLAH.

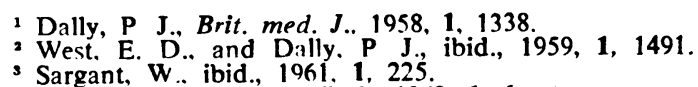

\section{Methrldopa and Depression}

SIR,-We have read with interest the letters by Dr. J. Mielczarek (December 1, 1962, p. 1471) and Dr. U. C. Dubach (January 26, p. 261) on the incidence of 
psychiatric disturbance after use of alpha-methyldopa ("aldomet"). In two recent series ${ }^{12}$ depression has occurred as a not uncommon side-effect of this drug. Smirk reported five cases who showed this symptom out of 53 patients treated and Hamilton et al. described three out of 69 hypertensives on methyldopa.

We would like to report a further case where gross psychiatric changes followed the administration of methyldopa but where the presentation was more like that of schizophrenia.

A woman aged 34 was admitted as an emergency at the 37th week of her third pregnancy suffering from preeclamptic toxaemia. Blood-pressure on admission was $160 / 120$ : there was marked oedema of hands. feet. face. and abdomen; and her urine contained $300 \mathrm{mg}$. protein per $100 \mathrm{ml}$. She complained of headache and visual disturbance. Treatment was instituted with intravenous infusion of 250 $\mathrm{ml} .5 \%$ dextrose containing $100 \mathrm{mg}$. chlorpromazine. $100 \mathrm{mg}$. promethazine. and $100 \mathrm{mg}$. pethidine. After a second similar infusion her blood-pressure fell to $140 / 100$ and she no longer complained of headache or blurred vision. She was put on methyldopa $250 \mathrm{mg}$. t.d.s., and the dosage raised to $500 \mathrm{mg}$. t.d.s. over a period of three days. and she was thus maintained. After five days she had a normal delivery of a live male infant. Forty-eight hours later, while she was still having methyldopa and had been given a total of $7 \mathrm{~g}$. of the drug. she developed psychotic symptoms.

She was dull and retarded and showed marked flattening of affect. presenting the picture of apathetic inertia. She experienced visual, olfactory and tactile hallucinations, and expressed ideas of reference. A diagnosis of toxic psychosis was made and treatment established with intravenous "parentrovite." She made an excellent recovery and was discharged on the tenth day of the puerperium.

The toxic psychoses may present widely varying clinical pictures, it being generally accepted that the character of such an illness is to some extent dictated by the pre-morbid personality of the patient. It seems to us possible that the preponderance of depressions reported following methyldopa may be due to the fact that most of the patients treated with this substance were "hypertensives" and might therefore be expected to possess close similarities of personality. A series of patients suffering from hypertension in pregnancy and treated with methyldopa might well show up a greater variety of psychiatric syndromes than has already been described.

We would like to thank Mr. D. R. Beaton for permission to publish this case.

-We are. etc.,

Herrison Hospital, Dorchester, Dorset.

Portwey Hospital,

Weymot th Dorset.

\section{A. G. Fullerton.}

D. MORTON-JENKINS.

REFERENCES

' Smirk, H., Brit. med. J.. 1963, 1. 146

2 Hamilton, M., and Kopelman, H., ibid., 1963, 1, 151

\section{Side-effects of Monoamine Oxidase Inhibitors}

SiR.-We are studying the incidence and mechanism of undesirable reactions when patients who are being treated with monoamine oxidase inhibitors receive pethidine or opium derivatives. So far as we can trace, only about 12 cases have been reported. whereas we have observed three of these ourselves in this hospital, and suspect that the incidence may be widespread.

We are anxious to discover (1) whether this is a common and invariably alarming complication. or (2) whether it depends upon a rare idiosyncrasy. In view of the wide use of monoamine oxidase inhibitors

it seems important to clarify this issue. We should therefore be grateful if this could be brought to the notice of your readers, and we should be obliged if we could have clinical details of any reactions observed, and also a note of any patients who have been known to have received such a combination without ill effects. -We are, etc.,

$$
\begin{aligned}
& \text { St. Thomas's Hospital, } \\
& \text { London S.E.1. }
\end{aligned}
$$

J. J. BRADley.

J. G. Francis.

\section{"Caprin"}

SIR,-I wonder whether I might inquire through your correspondence columns about the experiences of others who may have used a relatively new formulation of aspirin called "caprin"? This product is claimed by West Pharmaceutical Company Limited, the manufacturer, to be free of gastric irritant properties and is advertised as being ". . . the answer to painful gastric irritation and occult blood loss in long term, high dosage aspirin therapy."

These surprising claims are unsupported by evidence from clinical trials in man. Indeed, in recent correspondence with me the medical department of the company has maintained that "clinical trials in the case of caprin are not necessary because the therapeutic action of the drug is not in question." Furthermore, no investigation of intestinal blood loss has been carried out by them because "our claim is limited to the effect of caprin on the gastric mucosa."

In circumstances like these one may well question the reliability of the product concerned, and it would be most interesting to know whether anyone else has come to a similar conclusion after using it. Certainly in my limited experience caprin has proved just as capable of producing epigastric discomfort as are "ordinary" aspirin tablets. - I am, etc.,

$$
\text { Lancaster. }
$$

\section{B. W. McGuinNESS}

\section{Antibiotic Growth Stimulation}

SIR,-At this Institute we have been studying the mechanism of antibiotic growth stimulation for several years and feel that your annotation on antibiotics as human food supplements (December 15, 1962, p. 1594) calls for some comment. You list three serious objections to the participation of bacteria in antibiotic growth stimulation: (1) The small amount of antibiotic required to produce the effect; (2) the effective antibiotics have radically different structure, antibacterial spectra, and pharmacological properties; and (3) the response of germ-free animals to feeding with antibiotics.

We have reported' that low concentrations of penicillin included in the diet of chicks and resulting in a growth response usually eliminate Clostridium welchii from their caeca. When $\mathrm{Cl}$. welchii was not eliminated its toxigenicity was impaired. The fact that differing antibiotics such as penicillin, aureomycin, streptomycin, oleandomycin, etc., all stimulate growth has been quoted by an eminent authority ${ }^{2}$ as evidence for the participation of bacteria in this phenomenon. since the only factor the antibiotics have in common is an antibacterial one.

The crux of the matter lies in the response of germfree animals to antibiotics. Luckey, whom you quote, ${ }^{3}$ is the only worker who has reported the stimulation of growth of the germ-free animal by antibiotics; he used an even lower level than other workers. These experiments have been severely criticized by Jukes, ${ }^{4}$ 